\title{
Spontaneous deposition of Pt-nanoparticles on HOPG surfaces
}

\author{
José J. Arroyo Gómez and Silvana G. García*
}

Pt nanoparticles were spontaneously generated by immersion of a highly ordered pyrolytic graphite substrate in a $1 \mathrm{mM}$ $\mathrm{H}_{2} \mathrm{PtCl}_{6}+0.05 \mathrm{M} \mathrm{H}_{2} \mathrm{SO}_{4}$ plating solution using different immersion times, modifying both size and density of the deposits. Atomic force microscopy images show Pt particles distributed preferentially on surface defects of the electrode, increasing their size and density with deposition time. Scanning electronic microscopy/energy-dispersive X-ray spectroscopy images confirmed the formation of Pt deposits after $\mathbf{2} \mathrm{h}$ immersion, forming irregular agglomerates with different sizes distributed over the surface. The open circuit potential studies showed potentials close to the corresponding $\mathrm{PtCl}_{6}{ }^{2-} / \mathrm{Pt}$ and $\mathrm{PtCl}_{4}{ }^{2-} / \mathrm{Pt}$ couples, which would indicate that some of these processes took place at the interface. The voltammetric response of the supported Pt nanoparticles showed an increase in current density towards the hydrogen evolution reaction being more pronounced for deposits formed after an immersion time of $\mathbf{2} \mathbf{~}$. In this case, the voltammetric behavior was similar to polycrystalline Pt. Copyright $\odot 2015$ John Wiley \& Sons, Ltd.

Keywords: platinum; spontaneous deposition; HOPG; STM; ordered structures

\section{Introduction}

Carbon-supported Pt nanoparticles are object of interest because of their numerous applications, mainly in the development of electrocatalysts in fuel cells. ${ }^{[1-3]}$ Some properties, such as activity and selectivity for certain types of reactions, are determined by the structure and shape of the formed crystallites. These nanostructures can be obtained using different methods such as chemical reduction, ${ }^{[2]}$ atomic layer deposition, ${ }^{[4]}$ and electrochemical deposition ${ }^{[5-8]}$ being the last one the most reliable, efficient, and with the lowest cost way to generate Pt nanoparticles.

Few works ${ }^{[9-12]}$ have referred to the spontaneous deposition of Pt on highly ordered pyrolytic graphite (HOPG) substrates. For example, Zoval et al. ${ }^{[9]}$ found by noncontact atomic force microscopy (AFM) experiments that Pt could be spontaneously formed on the surface of these substrates in a $1.0 \mathrm{mM}$ $\mathrm{PtCl}_{6}{ }^{2-}+0.10 \mathrm{M} \mathrm{HCl}$ solution, without applying any external voltage. In order to obtain a narrow particle size distribution, the authors proposed a method to prevent the spontaneous deposition by anodically protecting the graphite electrode. Shen et al. ${ }^{[10]}$ observed this phenomenon in tapping mode AFM (TM-AFM) images, when a piece of highly orientated pyrolytic graphite was immersed in acetonitrile containing $\mathrm{PtCl}_{6}{ }^{2-}$. In addition, the authors analyzed that the disordered Pt particles formed could be reconstructed to more uniform and smaller nanoparticles by negatively charging the sample with a microsecond scale current pulse. Lu et al., ${ }^{[11]}$ using the same particle characterization method (TM-AFM), also found that Pt deposition could occur at opencircuit potential on HOPG from $\mathrm{H}_{2} \mathrm{PtCl}_{6}$ solutions without supporting electrolyte, resulting in a wide particle size distribution but, unlike to that observed by Zoval et al., ${ }^{[9]}$ they detected no preferential island growth at edge sites. Kokkinidis et al. ${ }^{[13,14]}$ also found that $\mathrm{Pt}$ can be deposited on a titanium surface from aqueous $\mathrm{HClO}_{4}$ solutions containing $\mathrm{K}_{2} \mathrm{PtCl}_{6}$. The mechanism is not yet well understood but it would be related to the presence of incompletely oxidized functionalities on graphite surface, which supply the necessary reducing equivalents. ${ }^{[9]}$

In this work, new insights of spontaneously deposited Pt nano-

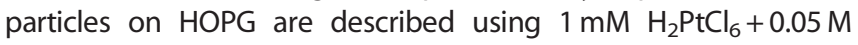
$\mathrm{H}_{2} \mathrm{SO}_{4}$ solution. The platinum nanostructures were characterized electrochemically by cyclic voltammetry and morphologically by ex situ scanning tunneling microscopy (STM), AFM, and scanning electronic microscopy (SEM) with energy-dispersive X-ray spectroscopy (EDX).

\section{Experimental}

Pt nanoparticles were spontaneously deposited on a HOPG SPI-2 grade substrate (SPI Supplies, USA), which was prepared by cleaving the surface with an adhesive tape immediately prior to each experiment. The electrode was held within a Teflon holder that provided for the exposure of a $0.216 \mathrm{~cm}^{2}$ area of the HOPG basal plane to the plating solution using a Teflon O-ring.

The spontaneous formation of the Pt nanoparticles on HOPG was performed from a $1 \mathrm{mM} \mathrm{H}_{2} \mathrm{PtCl}_{6}+0.05 \mathrm{M} \mathrm{H}_{2} \mathrm{SO}_{4}$ solution, prepared from suprapure chemicals (E. Merck, Darmstadt) and tri-distilled water. All the experiments were carried out at a temperature of $T=298 \mathrm{~K}$ using a conventional three-electrode electrochemical cell. The counter electrode was a Pt sheet $\left(1 \mathrm{~cm}^{2}\right)$, and the reference electrode was a satured calomel electrode (SCE, $E_{S C E}=0.2415 \mathrm{~V}$ vs $\mathrm{SHE}$ ). All potentials given in this paper are referred to this electrode.

\footnotetext{
* Correspondence to: S. G. García, Instituto de Ingeniería Electroquímica y Corrosión (INIEC), Dpto. de Ingeniería Química, Universidad Nacional del Sur, Avda. Alem 1253, 8000 Bahía Blanca, Argentina.

E-mail: sgarcia@criba.edu.ar
}

Instituto de Ingeniería Electroquímica y Corrosión (INIEC), Dpto. de Ingeniería Química, Universidad Nacional del Sur, Avda. Alem 1253, 8000 Bahía Blanca, Argentina 
The experiences were recorded using a computer-controlled EG\&G Princeton Applied Research model 273A potentiostat-galvanostat. The morphology and size of Pt nanoparticles were characterized by ex situ STM and AFM, using a standard Nanoscope III microscope (Digital Instruments, Santa Barbara, USA) and also by SEM using a JEOL 35CF microscope integrated with an EDX DX-4 analyzer.

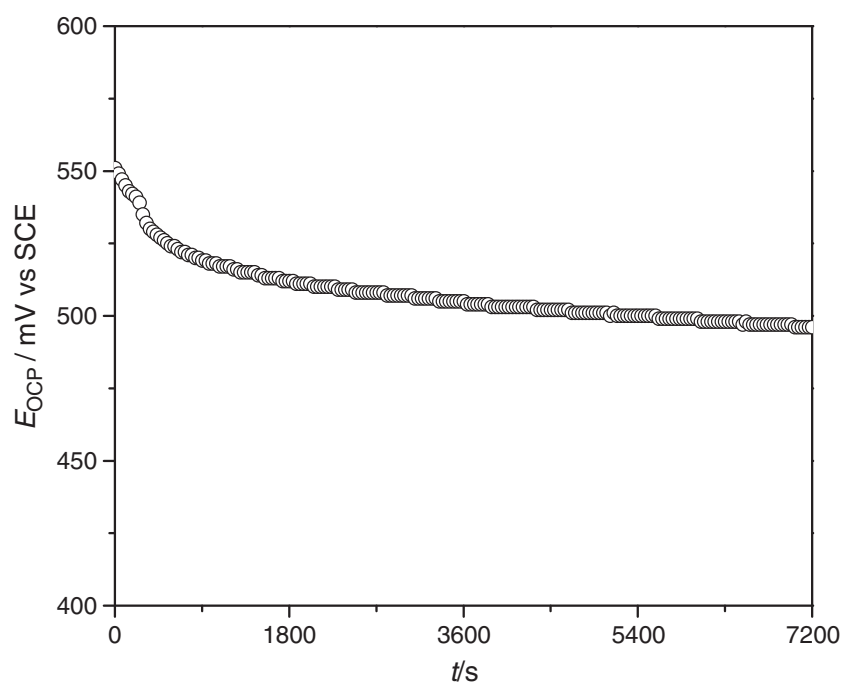

Figure 1. Time evolution of the open circuit potential $\left(E_{\mathrm{OCP}}\right)$ of HOPG immersed in $1 \mathrm{mM} \mathrm{H}_{2} \mathrm{PtCl}_{6}+0.05 \mathrm{M} \mathrm{H}_{2} \mathrm{SO}_{4}$.
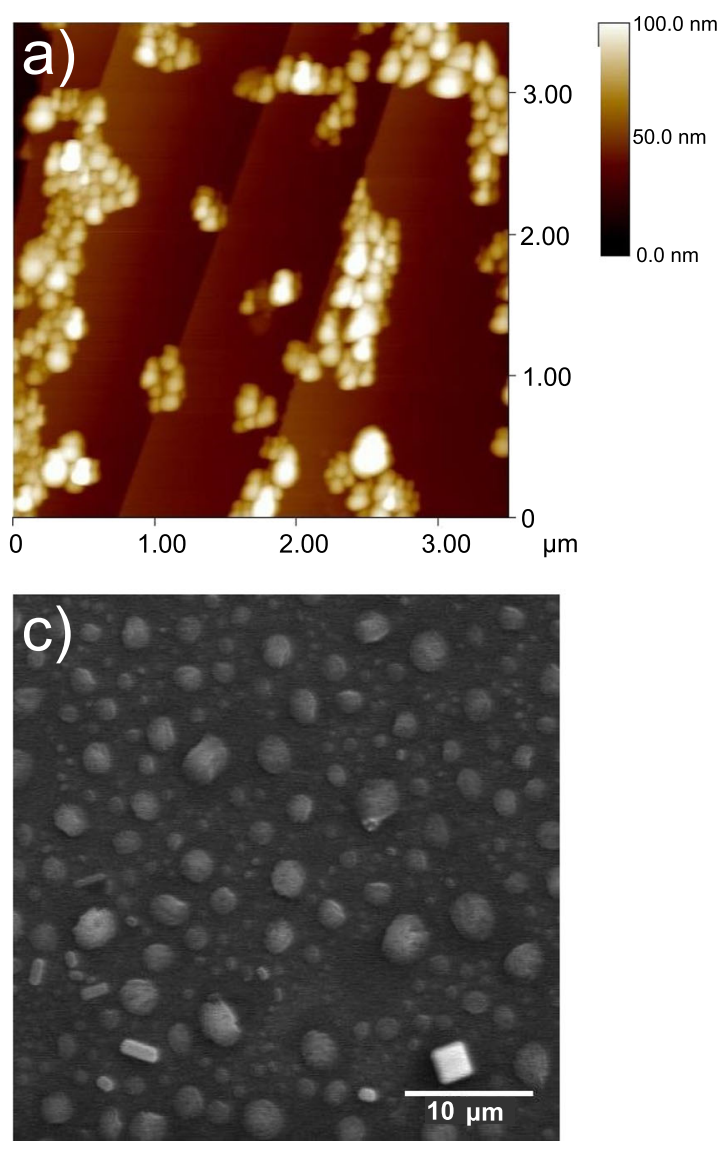

Figure 2. AFM images of the Pt-modified HOPG surface obtained after (a) $2 \mathrm{~h}$, (b) $3 \mathrm{~h}$ immersion time, (c) 1500X SEM image after $2 \mathrm{~h}$ deposition time, and (d) EDX spectrum of (c).

\section{Results and discussion}

\section{Open circuit potential analysis}

As it was mentioned in the preceding texts, it is well known that $\mathrm{Pt}$ spontaneously reduces itself from chloride solutions on HOPG; i.e., the deposition takes place at open circuit potential ( $\left.E_{\mathrm{OCP}}\right)$. In this case, the spontaneous deposition of Pt on HOPG electrodes was carried out from a $1 \mathrm{mM} \mathrm{H} \mathrm{PtCl}_{6}+0.05 \mathrm{M} \mathrm{H}_{2} \mathrm{SO}_{4}$ solution with immersion times ranged between $200 \mathrm{~s}$ and $3 \mathrm{~h}$, in order to evaluate the density and size of the formed deposits. Figure 1 shows the time evolution for the $E_{\mathrm{OCP}}$ of HOPG after the immersion in the hexachloroplatinic acid solution for one experiment. The responses for all the performed experiments indicated that the open circuit potential was always comprised between $480 \leq E_{\mathrm{OCP}} /$ $m V \leq 570$, that it could be attributed to the different grades of surface oxidation. ${ }^{[9]}$ In some cases, the $E_{\mathrm{OCP}}$ values were close to the redox potential $\mathrm{PtCl}_{6}{ }^{2-} / \mathrm{Pt}$ and $\mathrm{PtCl}_{4}{ }^{2-} / \mathrm{Pt}$ couples, according to $\mathrm{Lu}$ and Zangari: ${ }^{[8]}$

$$
\begin{array}{ll}
\mathrm{PtCl}_{6}^{2-}+4 e^{-} \rightarrow \mathrm{Pt}+6 \mathrm{Cl}^{-} & E^{0}=502 \mathrm{mV} \text { vs SCE } \\
\mathrm{PtCl}_{4}^{2-}+2 e^{-} \rightarrow \mathrm{Pt}+4 \mathrm{Cl}^{-} & E^{0}=516 \mathrm{mV} \text { vs SCE }
\end{array}
$$

The electrodeposition of Pt from chloroplatinic acid involves three steps corresponding to reactions in Eqns (1) and (2)
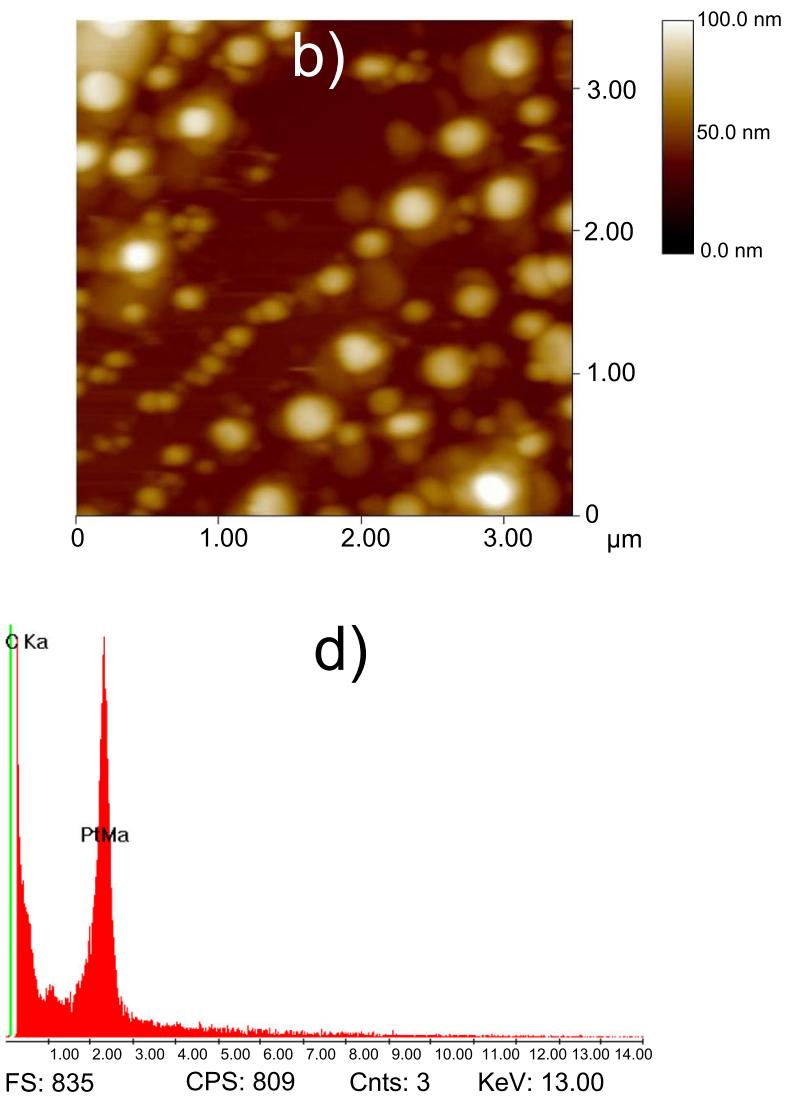
including a previous one related to the electroreduction of $\mathrm{PtCl}_{6}{ }^{2-}$ to $\mathrm{PtCl}_{4}{ }^{2-}$ species according to Feltham and Spiro: ${ }^{[15]}$

$$
\mathrm{PtCl}_{6}^{2-}+2 e^{-} \rightarrow \mathrm{PtCl}_{4}^{2-}+2 \mathrm{Cl}^{-} \quad \mathrm{E}^{0}=485 \mathrm{mV} \text { vs SCE }
$$

However, this reaction, as reported Zangari et al., ${ }^{[8]}$ underwent fast reduction or disproportionation at low chloride concentration, particularly when $\mathrm{H}_{2} \mathrm{SO}_{4}$ is used as supporting electrolyte.
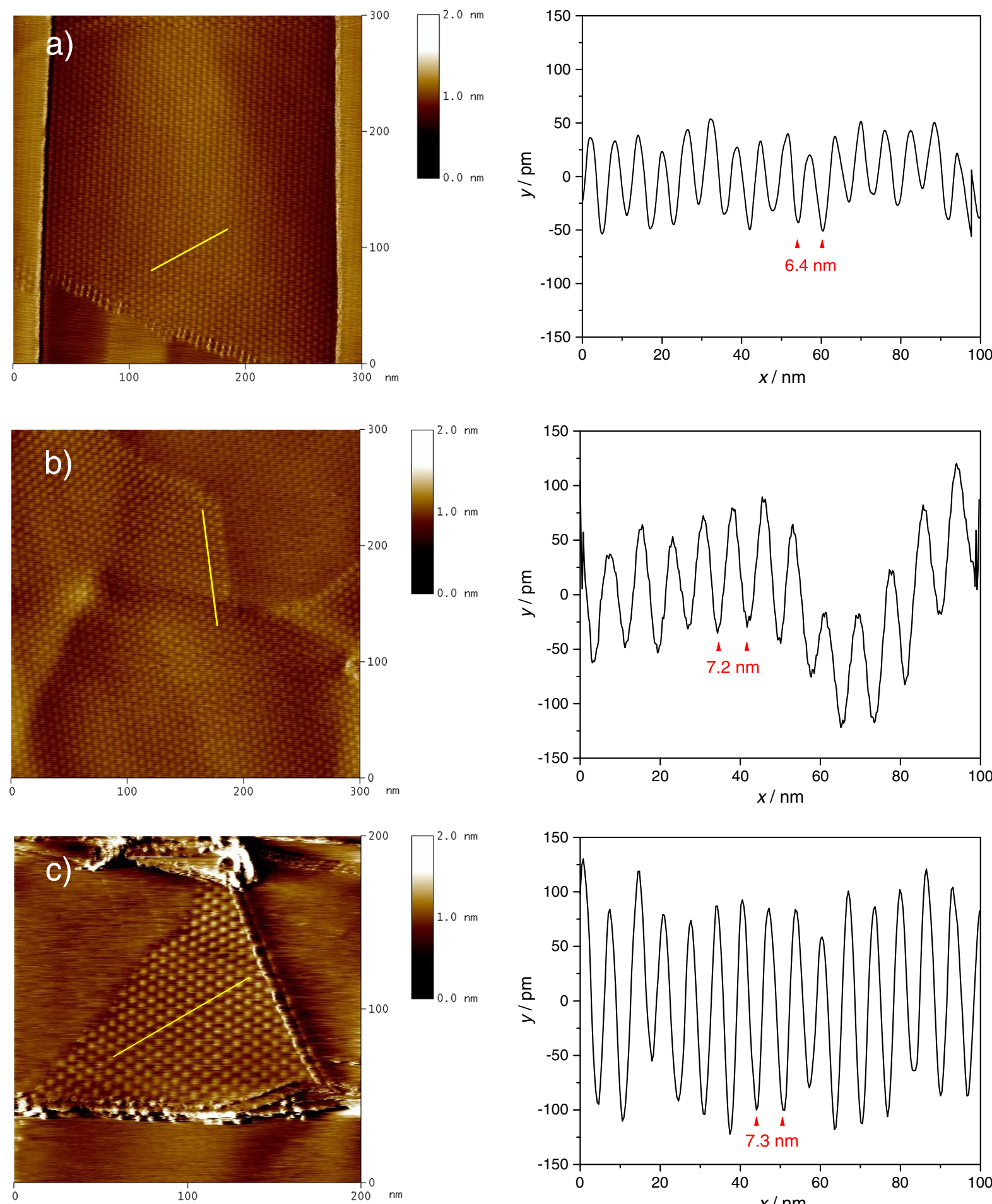

Therefore, the obtained values of the OCP curves indicate that some of the reactions in Eqns (1) and (2) are taking place spontaneously on the electrode surface, these values are similar to those reported for $1 \mathrm{mM} \mathrm{H}_{2} \mathrm{PtCl}_{6}$ without supporting electrolyte (about $550 \mathrm{mV}$ ), ${ }^{[11]}$ and within the potential range indicated for $0.01 \mathrm{M} \mathrm{H}_{2} \mathrm{PtCl}_{6}$ in $0.1 \mathrm{M} \mathrm{HCl}$ solution $(560-660 \mathrm{mV}) .^{[12]}$

Taking into account that these steps are possible to occur at the HOPG surface without an external flow of electric charge, the
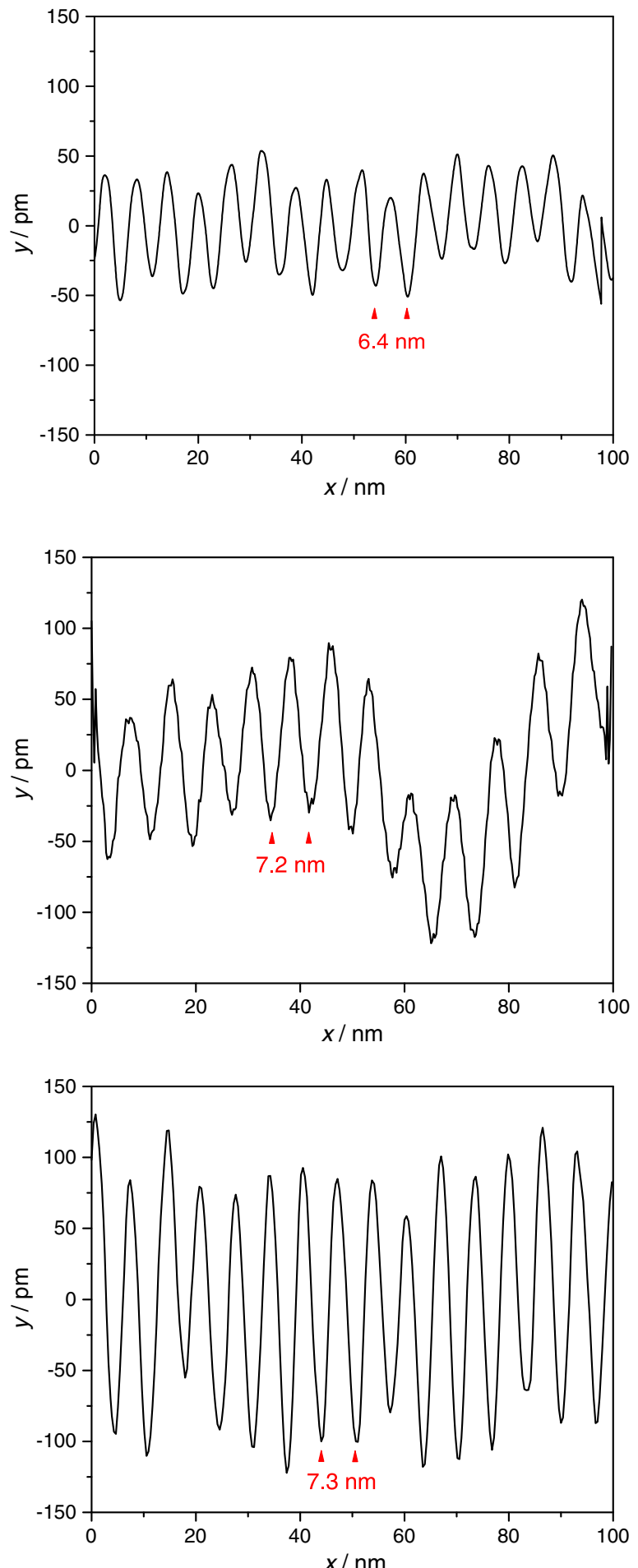

Figure 3. STM images and the corresponding cross sections of nanostructures organized in a regular hexagonal pattern on HOPG surface obtained at different immersion times: (a) $200 \mathrm{~s}$, (b) $2 \mathrm{~h}$, and (c) $3 \mathrm{~h}$. 
mechanism of spontaneous deposition is not very clear but it can be explained by the presence of incompletely oxidized functionalities (alcohols, ketones, etc.) at step edges of the substrate, which work as reduction sites for the platinum ions in solution. ${ }^{[9]}$ However, the complete mechanism of this process is not entirely understood, and for example, it fails to explain why others metals, such as silver, with a more positive reduction potential than platinum are not spontaneously deposited on HOPG. Some authors ${ }^{[10]}$ also indicated that as the surface carbon atoms on HOPG could be hydrogen terminated, these hydrogen atoms would act as reducing agents together with other functionalities, facilitating the reduction from $\mathrm{PtCl}_{6}{ }^{2-}$ to $\mathrm{Pt}$ or $\mathrm{PtCl}_{4}{ }^{2-}$, which can also be reduced to form metallic Pt [Eqns (1) and (2)].

\section{Morphologic analysis}

Pt deposits formed on HOPG electodes were characterized by ex situ STM, AFM, and SEM. Figure 2 shows the Pt-modified HOPG surface via spontaneous deposition at different immersion times exhibiting the preferential deposition of Pt on step edges, followed by the formation of large metal clusters. The deposition occurred also on terraces as the immersion time increased.

AFM images show that after $2 \mathrm{~h}$ immersion, the Pt nucleates on the HOPG step edges forming irregular agglomerates (Fig. 2a) with an average height of $76 \mathrm{~nm}$ and an average mean size of $273 \mathrm{~nm}$. At longer immersion times $(3 \mathrm{~h}$ ), large clusters formed mainly by hemispherical particles of different sizes were recorded almost entirely covering the electrode surface, with sizes up to $250 \mathrm{~nm}$ and heights between 125 and 200 nm, as evidenced in Fig. 2b. SEM (Fig. 2c) corroborates the formation of Pt particles of different sizes and shapes, distributed over the surface. EDX analysis, besides the signal corresponding to the carbon substrate, confirmed the presence of Pt in the sample.

In certain regions, however, a well-defined structure was observed on the HOPG surface for different immersion times, as it is shown in Fig. 3. The corresponding cross section was also included. This structure was not observed before under these experimental conditions and coexist with Pt particles and agglomerates on the HOPG substrate surface. Figure 3a shows highly ordered arrays of spherical segments of nanoparticles with an average diameter of 6.4 and $0.15 \mathrm{~nm}$ height. The particles observed at a deposition time of $2 \mathrm{~h}$, retained the same order but the diameter $(7.2 \mathrm{~nm})$ as well as the height $(0.2 \mathrm{~nm})$ increased. After $3 \mathrm{~h}$ immersion time (Fig. $3 \mathrm{c})$, the particle diameter increased slightly to $7.4 \mathrm{~nm}$, but the height doubled to $0.4 \mathrm{~nm}$. The question then arises on the nature of the observed nanoparticles organized in a regular hexagonal pattern on HOPG, Pt, or C. It was found in the literature ${ }^{[16,17]}$ that there is an anomaly of the STM related to superlattices on graphite, which are formed because of intrinsic defects of the substrate generated during crystal growth or cleavage. In principle, these particles could be associated to a graphite structure generated from the preparation of the surface before each experiment. This structure with a given periodicity may serve as a template for the subsequent $\mathrm{Pt}$ deposit organization which, in this case, could be evidenced in the diameter and/or height changes of the particles with immersion time. Self-organization of Pt was found on graphite in UHV. ${ }^{[18]}$ Thereby, the metal spontaneous deposition could be influenced by these arrays of nanostructures. Anyway, further studies are in progress in order to determine the real nature of the particles.

\section{Electrocatalytic activity of modified electrodes}

In order to analyze qualitatively the electrocatalytic activity of the Pt-modified HOPG surfaces, cyclic voltammograms of clean HOPG and after immersion in the solution containing $\mathrm{PtCl}_{6}{ }^{2-}$ ion at different times were performed in a $0.5 \mathrm{M} \mathrm{H}_{2} \mathrm{SO}_{4}$ test solution. The voltammetric results are shown in Fig. 4. The activation of the electrode by presence of Pt is evident (Fig. 4a), beginning the hydrogen evolution earlier at approximately -460 and $-350 \mathrm{mV}$ after $200 \mathrm{~s}$ and $2 \mathrm{~h}$ immersion time, respectively. The current density for this reaction increases with deposition time, which can be related with a higher Pt load at longer times. This behavior has been reported for Pt nanowires obtained spontaneously on $\mathrm{HOPG}^{[12]}$ and for $\mathrm{Pt}$ hollow nanospheres and solid nanoparticles supported on graphene and Pt/graphene-modified glassy carbon. ${ }^{[19]}$ After longer immersion times $(\geq 2 \mathrm{~h}$ ) the cyclic voltammogram was quite similar to polycrystalline platinum as evidenced in Fig. 4b). In the cathodic direction the reduction of Pt oxide is observed in the potential region $200 \leq E / \mathrm{mV} \leq 600$ followed by the hydrogen adsorption on $\mathrm{Pt}$ at more negative potentials. In the anodic direction, the corresponding desorption of hydrogen and the Pt oxide region at potentials more positive that $600 \mathrm{mV}$ is evidenced.
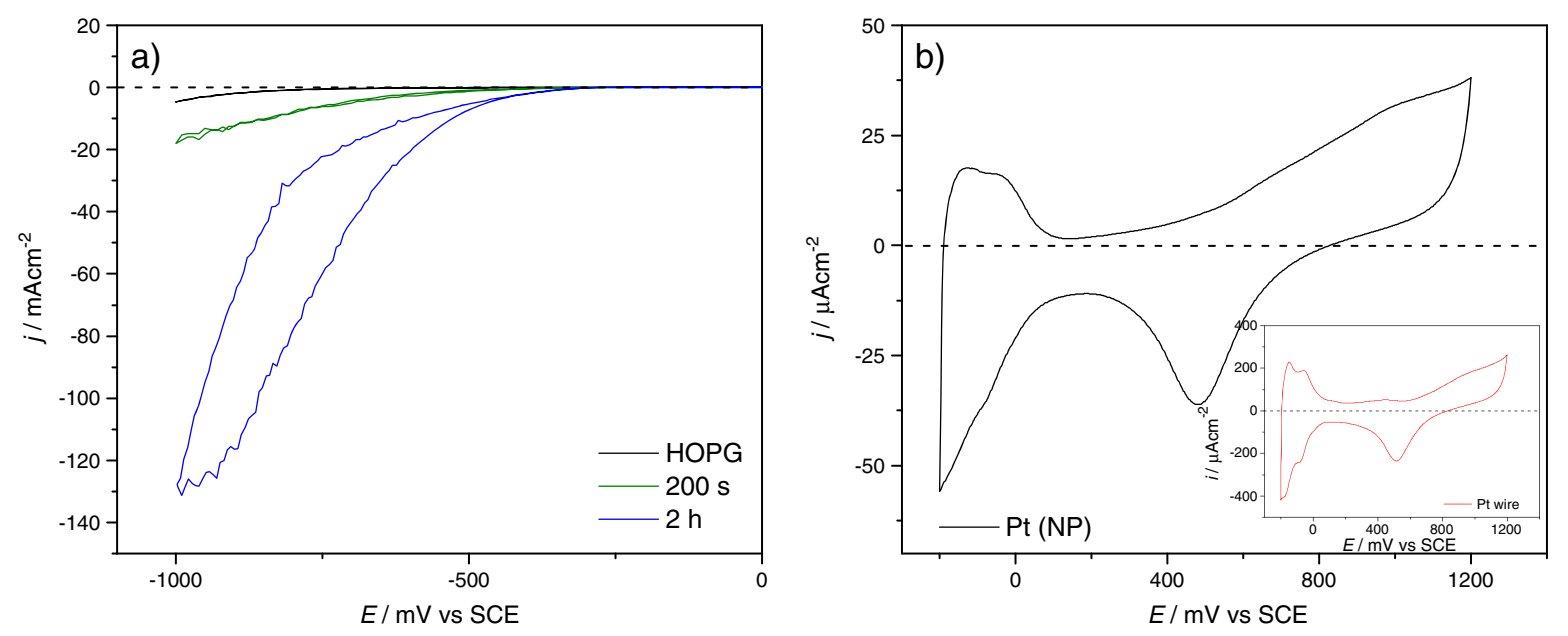

Figure 4. Cyclic voltammograms in $0.5 \mathrm{M} \mathrm{H}_{2} \mathrm{SO}_{4}$ of (a) clean HOPG surface and Pt-modified surfaces, after $200 \mathrm{~s}$ and $2 \mathrm{~h}$ deposition time, $|\mathrm{d} E / \mathrm{d} t|=10 \mathrm{mV} / \mathrm{s}$, and (b) polycrystalline Pt and Pt-modified HOPG surface after $2 \mathrm{~h}$ deposition time, $|\mathrm{d} E / \mathrm{dt} t|=50 \mathrm{mV} / \mathrm{s}$. 


\section{Conclusions}

Platinum nanoparticles have been obtained on HOPG by spontaneous deposition from hexachloroplatinic acid solutions. Open circuit potential curves show that under the experimental conditions, the potential was close to those of the $\mathrm{PtCl}_{6}{ }^{2-} / \mathrm{Pt}$ and $\mathrm{PtCl}_{4}{ }^{2-} / \mathrm{Pt}$ couples, indicating that some of these processes could take place spontaneously.

AFM images show Pt deposits at different immersion times exhibiting the preferential deposition of Pt on step edges, followed by the formation of large metal clusters. The deposition occurs also on terraces as the immersion time increased. At longer immersion times $(3 \mathrm{~h})$, large clusters formed mainly by hemispherical particles of different sizes were recorded almost entirely covering the electrode surface, which was corroborated by SEM. EDX analysis confirmed the presence of Pt on the surface.

The supported Pt nanoparticles show an electrocatalytic effect for the hydrogen evolution reaction being more pronounced for particles prepared at longer deposition times and, therefore, with the amount of Pt generated on the surface. In this case, the voltammetric response became similar to that of polycrystalline Pt.

\section{Acknowledgements}

The authors wish to thank the Universidad Nacional del Sur (Argentina) and CONICET (PIP-0853) for the financial support of this work. J.J. Arroyo Gómez acknowledges a fellowship granted by CONICET.

\section{References}

[1] S. H. Hsieh, M. C. Hsu, W. L. Liu, W. J. Chen, Appl. Surf. Sci. 2013, $277,223$.

[2] G. Xia, C. Huang, Y. Wang, Int. J. Hydrogen Energ. 2013, 38, 13754.

[3] E. Antolini, J. Mater. Sci. 2003, 38, 2995.

[4] H. B. R. Lee, S. H. Baeck, T. F. Jaramillo, S. F. Bent, Nano Lett. 2013, 13, 457.

[5] E. C. Walter, M. P. Zach, F. Favier, B. J. Murray, K. Inazu, J. C. Hemminger, R. M. Penner, ChemPhysChem 2003, 4, 131.

[6] M. M. E. Duarte, A. S. Pilla, J. M. Sieben, C. E. Mayer, Electrochem. Commun. 2006, 8, 159.

[7] T. Brülle, U. Stimming, J. Electroanal. Chem. 2009, 636, 10.

[8] G. Lu, G. Zangari, J. Phys. Chem. B 2005, 109, 7998.

[9] J. V. Zoval, J. Lee, S. Gorer, R. M. Penner, J. Phys. Chem. B 1998, 102, 1166.

[10] P. Shen, N. Chi, K. Y. Chan, D. L. Phillips, Appl. Surf. Sci. 2001, 172, 159.

[11] G. Lu, G. Zangari, Electrochim. Acta 2006, 51, 2531.

[12] P. M. Quiano, M. R. Gennero de Chialvo, M. E. Vela, R. C. Salvarezza, J. Argent. Chem. Soc. 2005, 93, 215.

[13] G. Kokkinidis, A. Papoutsis, D. Stoychev, A. Milchev, J. Electroanal. Chem. 2000, 486, 48.

[14] G. Kokkinidis, D. Stoychev, V. Lazarov, A. Papoutsis, A. Milchev, J. Electroanal. Chem. 2001, 511, 20.

[15] A. M. Feltham, M. Spiro, Chem. Rev. 1971, 71, 177.

[16] W. Pong, J. Bendall, C. Durkan, Jpn. J. Appl. Phys. 2005, 44, 5443.

[17] W. Pong, C. Durkan, J. Phys. D Appl. Phys. 2005, 38, R329.

[18] L. Bardotti, F. Tournus, P. Mélinon, M. Pellarin, M. Broyer, Eur. Phys. J. D 2011, 63, 221.

[19] R. Ojani, R. Valiollahi, J.-B. Raoof, Energy 2014, 74, 871. 